\title{
Editorial
}

\section{A stark glimpse of challenges for tomorrow}

This year we mark a milestone in the history of public health by hosting the $44^{\text {th }}$ Asia Pacific Academic Consortium For Public Health (APACPH) conference in Colombo, Sri Lanka from the $14^{\text {th }}-17^{\text {th }}$ October 2012 . This conference is hosted by the Faculty of Medicine, University of Colombo. This conference would assist the public health personnel's to pave the way towards meeting the challenges in Public Health in the future.

In this issue, we have published the Presidential address given by Dr. Vinya Ariyaratne titled "Role of primary health care in the $21^{\text {st }}$ century" and the way forward, gives a glimpse of the challenges that primary health care services had gone through in the past and what we would encounter in the future. The college oration on the topic titled "maternal mortality ratio in Sri Lanka towards a single digit" is of importance since Sri Lanka is now challenged by reducing maternal mortality further.
Teenage marriage and pregnancies, which are on the rise, is of concern and another dare for the Sri Lankan public health specialists. The authors have analysed the data from three sources to describe the prevalence, trends and district differentials of teenage pregnancies in Sri Lanka.

In the original research articles titled "an evaluation of health care waste management in the Base Hospitals of Colombo District" highlights the importance of improving knowledge, attitudes and practices among the nursing officers. Finally we have a short communication titled "self- perceived burden on childcare on mother -substitutes of children of migrant women". The author has highlighted the health effects and burden of primary carers and concludes that adequate support services and policies needs to be established to ensure the benefits are optimally utilized by them.
Hony. Editor

Dr. Sampatha Goonewardena
Co. Editor

Dr. Shamini Prathapan

Department of Community Medicine, Faculty of Medical Sciences, University of Sri Jayewardenepura, Nugegoda. 